\title{
Distribution of Tankyrase-1 mRNA expression in colon cancer and its prospective correlation with progression stage
}

\author{
STEFANIA GELMINI $^{1}$, MELISSA POGGESI ${ }^{1}$, PAMELA PINZANI ${ }^{1}$, SARA CIULLINI MANNURITA $^{1}$, \\ FABIO CIANCHI $^{2}$, ROSA VALANZANO ${ }^{3}$ and CLAUDIO ORLANDO ${ }^{1}$ \\ ${ }^{1}$ Clinical Biochemistry Unit, Department of Clinical Physiopathology, ${ }^{2}$ Department of General Surgery, ${ }^{3}$ Surgery Unit, \\ Department of Clinical Physiopathology, University of Florence, viale Pieraccini 6, Florence 50139, Italy
}

Received May 17, 2006; Accepted June 19, 2006

\begin{abstract}
We tested Tankyrase-1 mRNA expression in colon cancer patients to evaluate the prognostic role of this parameter by real-time RT-PCR in a retrospective group of 82 unselected patients with colon cancer. Paired cancer and corresponding not affected tissues were used. Laser-assisted microdissection was used to measure Tankyrase-1 mRNA in homogeneous cancer cell populations and in normal colon epithelium of the same patients. Tankyrase- 1 mRNA in colon cancers, as a mean, was significantly higher than in paired not affected tissues $(\mathrm{p}<0.0001)$, but its level correlates inversely with a cancer progression stage. Survival analysis indicated that lower Tankyrase-1 mRNA expression in colon cancers was significantly associated to reduced patient survival $(p=0.019)$ and disease-free interval $(\mathrm{p}=0.035)$, confirmed also in a multivariate analysis.
\end{abstract}

\section{Introduction}

The morphologic and molecular events of colon cancer occur via a multistep pathway (1). A number of histopathological studies indicate that the majority of colorectal tumors arise from adenomatous polyps, with a progression of the small adenoma to a larger lesion and subsequently to a carcinoma (2). By molecular genetic studies considerable advances in the molecular understanding of colorectal cancer have been made with the identification of mutations of the adenomatous polyposis coli gene, $5 q$ chromosomal mutations, ras oncogene expression, deletion of chromosome 18 and allelic loss of DCC and p53, mutational activation of oncogenes, deletion and allelic loss (3). Another important step of colorectal carcinogenesis of colon tumors is the acquisition of immortality. Telomeres and its associated proteins have been shown to be involved in the control of cell proliferation, in the regulation

Correspondence to: Dr Claudio Orlando, Clinical Biochemistry Unit, Department of Clinical Physiopathology, University of Florence, viale Pieraccini 6, Florence 50139, Italy

E-mail: c.orlando@dfc.unifi.it

Key words: telomere length, telomeric protein, real-time PCR, laser-assisted microdissection of cell senescence in most somatic cells, and in the unlimited proliferation of malignant cells (4).

Tumor cells need to compensate for replicative telomere losses to preserve their ability to proliferate indefinitely $(5,6)$. The extensive proliferation of cell during the prolonged multistep tumorigenesis pathway is predicted to exhaust the telomere reserve, necessitating telomerase activation (6-12). Telomere stability is believed to be accomplished by the action of other telomere-specific binding proteins. The enzyme Tankyrase-1, a telomeric poly(ADP-ribose) polymerase (PARP), was identified as a component of the human telomeric complex (13). PARPs catalyze formation of long chains of poly(ADP-ribose) onto protein acceptors using $\mathrm{NAD}^{+}$as a substrate. Tankyrase-1 interacts with the telomeric DNAbinding protein TRF1 (TTAGGG repeat binding factor 1) (14), a negative regulator of telomere length $(13,15-17)$. TRF1 is believed to act in cis at telomeres to regulate access of telomerase counteracting telomerase-mediated telomere elongation. Tankyrase-1 seems to inhibit TRF1 binding to telomeres through the Tankyrase-mediated ADP-ribosylation of TRF1 protein (13). Overexpression of Tankyrase-1 in the nucleus releases TRF1 from telomeres and induces telomere elongation indicating Tankyrase- 1 as a positive regulator of telomere length. Unlike telomerase, the expression of Tankyrase-1 would be expected ubiquitously distributed in all somatic cells but its expression is expected to be upregulated in all human tumors. Recent evidence confirmed this role also in vivo (18) reporting an increase of Tankyrase-1 expression in multiple myeloma and plasma cell leukemia and this upregulation was concomitant to the expression of human telomerase reverse transcriptase (hTERT) and telomerase RNA template (hTER) (19). Similar results were reported in patients with high-grade non-Hodgkins's lymphomas (20) and with breast cancers (21).

The aim of this study was to evaluate the level of mRNA expression of the Tankyrase- 1 gene by real-time PCR in colorectal cancers and in adjacent normal tissues. Microdissection experiments contributed to clarify Tankyrase-1 mRNA distribution in normal colon epithelium.

\section{Patients and methods}

Tissues were obtained from 82 patients with sporadic colorectal carcinoma (48 males and 34 females, age range: 


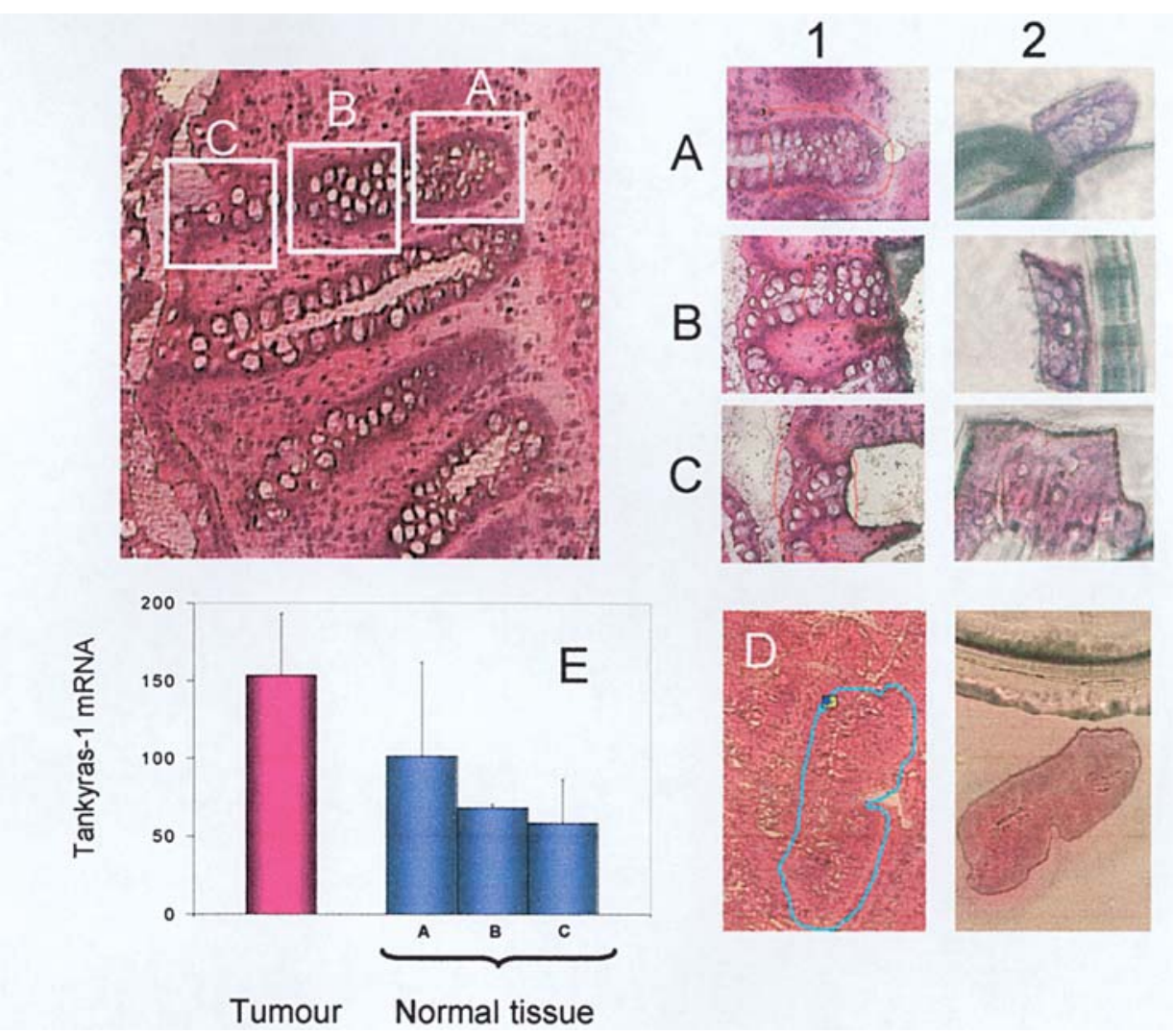

Figure 1. Example of laser-assisted microdissection of colon cancer (panel D) and paired not affected normal epithelia collected $10 \mathrm{~cm}$ apart from neoplastic lesion. In normal crypt three different areas were selected corresponding to the fondus (panel A), mainly composed by active proliferating cells, the medium part of the crypt wall (panel B) and superficial luminal cells (panel C). The microdissected area is indicated in panel 1, while in panel 2 the fragment catapulted after dissection is reported. Mean results of Tankyrase-1 mRNA/cell from six experiments are graphically reported in panel E.

48-89 years, mean $=66.9)$, scheduled for elective resection. Informed consent was previously obtained from all patients. For all of them at least one sample of both neoplastic and normal tissue (taken $10 \mathrm{~cm}$ apart from the neoplasm) were collected at surgery. Samples were immediately snap-frozen and stored in liquid nitrogen. Tumor was localized in the right colon in 32 patients, in the left colon in 28 patients ( 8 in the descending, and 20 in the sigmoid colon), and in the rectal portion in the remaining 22 patients. Histological examination was performed routinely in all cases. An adequate number of sections were sampled from each tumor. Slides were reviewed by the same pathologist without knowledge of real-time results. Tumor histotype and grade of differentiation were defined according to the World Health Organization criteria (22). The pattern of cancer growth was defined as expanding (when the tumor border was clearly demarcated; $\mathrm{n}=32$ ) and as infiltrating (when cancer cells spread into the surrounding tissues without a distinct border; $n=50)(23)$. All cases were staged according to the original Dukes' system: Dukes $\mathrm{A}=13$; Dukes $\mathrm{B}=39$, Dukes $\mathrm{C}=22$ and Dukes $\mathrm{D}=8$, respectively. According to the histopathological grading, 10 tumors were $\mathrm{G} 1,46$ were $\mathrm{G} 2,4$ were $\mathrm{G} 3$ and 12 were colloid; the other 4 showed a mixed pattern of G2 plus colloid. Six were in situ tumors. All patients received a comparable postsurgical therapy. The median follow-up for this group of patients was 43.8 months (maximum 64.6 months).

Total RNA from cancer and normal tissues was extracted with the RNeasy mini reagent kit (Qiagen, Milan, Italy), according to the manufacturer's recommendations. Total
RNA (400 ng) was reverse transcribed using TaqMan RT PCR kit (PE Applied Biosystems, Forster City, CA, USA). Reverse transcription was performed in a final volume of $80 \mu 1$ containing $500 \mathrm{mM} \mathrm{KCl}, 0.1 \mathrm{mM}$ EDTA, $100 \mathrm{mM}$ Tris- $\mathrm{HCl}$, $\mathrm{pH} 8.3,5.5 \mathrm{mM} \mathrm{MgCl} 2,500 \mu \mathrm{M}$ of each dNTP, $2.5 \mu \mathrm{M}$ of random examers, $0.4 \mathrm{U} / \mu 1$ of RNase inhibitor, $1.25 \mathrm{U} / \mu 1$ of Multiscribe Reverse Transcriptase according to the manufacturer's recommendations. Total RNA, isolated from DU145 cell line (human prostate cancer ATCC HTB 81) was used to generate a standard curve for the TaqMan assay. This cell line was chosen for the relative high expression of Tankyrase-1 mRNA expression.

Real-time RT-PCR. The primers and probe for the measurement of Tankyrase-1 mRNA expression were selected by the proprietary software 'primer express' (PE Applied Biosystems). The forward primer 5'-ATGCCCCCAGAGGCCTTAC-3' (2871-2879), reverse primer 5'-GGTGGATGCTGGTGA GATCA-3' (2932-2951) and fluorescent probe (FAM) 5'-CT GTTTTAAACCTCAGGCTACTGTAGTGAGTGCCT-3' (2894-2928) were obtained from the Tankyrase-1 gene sequence AF082556 (GenBank). Since other Tankyrase-1related genes kave also been identified and cloned (24), we tested the specificity of our primers and probe for Tankyrase-1 mRNA using the ExPASy program, as previously reported (21). In each sample the presence of GAPDH mRNA expression was also tested with the commercial kit GAPDH control reagent (PE Applied Biosystems) to exclude RNA degradation. 

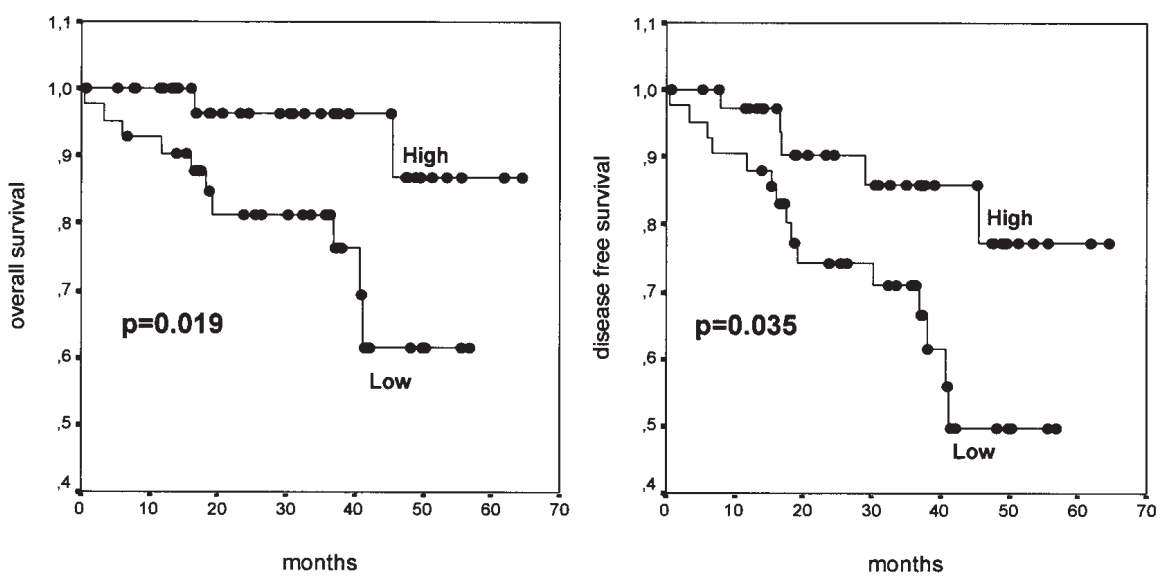

Figure 2. Cumulative cancer-related survival (left panel) and disease-free interval (right panel) in patients with high Tankyrase-1 mRNA expression ( $>44$ ng DU145 RNA $/ \mu$ g total RNA) compared to patients with low Tankyrase-1 mRNA expression ( $\leq 44$ ng DU145 RNA/ $\mu$ g total RNA). Survival distributions were calculated using the Kaplan-Meier method and compared by log-rank analysis.

The expression of Tankyrase-1 was calculated by referring to an external reference curve generated with total RNA extracted from the human prostate carcinoma DU145 cell line (from $25 \mathrm{ng}$ to $2.5 \mathrm{pg}$ of cDNA), overexpressing Tankyrase-1 mRNA. For each sample $25 \mathrm{ng}$ of cDNA were added to $25 \mu \mathrm{l}$ of PCR mix containing $300 \mathrm{nM}$ of each primer, 1X Universal master mix (PE Applied Biosystem) and $100 \mathrm{nM}$ of a fluorescent specific probe. The samples and the standards were then subjected to 40 cycles of amplification at $95^{\circ} \mathrm{C}$ for $15 \mathrm{sec}$ and $60^{\circ} \mathrm{C}$ for $60 \mathrm{sec}$ in the ABI Prism 7700 sequence detector (PE Applied Biosystems). The results were expressed in terms of equivalents of $n g$ DU145 RNA/ $\mu$ g total RNA.

Laser-assisted microdissection. Microdissection experiments were performed in a limited number of paired cancer and not affected tissues $(n=6)$, to measure Tankyrase- 1 mRNA in homogeneous clusters of colon cancer cells but also in basal compartment of intestinal cripts, in the medium of the cript and superficial luminal cells, all taken at $\sim 10 \mathrm{~cm}$ from the neoplastic lesion and expected to be not affected (Fig. 1). For microdissection we used the PALM laser-microbeam system (P.A.L.M. Microlaser Technologies AG, Bernried, Germany) which enables the contact-free isolation of single cells or group of cells. The sections were mounted onto a polyethylene naphthalate membrane slide according to the manufacturer's instructions. Frozen section were fixed with ethanol immediately after cutting in a cryostat, stained with H\&E followed by increasing ethanol series and air dried. The microdissected cells were catapulted into the lid of a $0.5-\mathrm{ml}$ reaction tube containing $5 \mu \mathrm{l}$ of catapult buffer $(20 \mathrm{mmol} / \mathrm{l}$ Tris pH 8.0; 2 mmol/l EDTA; 0.5\% Igepal CA-630 (SigmaAldrich, Milan, Italy) by means of the laser pressure catapulting technique of the instrument. RNeasy micro kit (Qiagen) was used for total RNA purification from the microdissected samples following the manufacturer's procedure for microdissected cryosections (RNeasy Micro Handbook 4/2003). A volume of $12 \mu \mathrm{l}$ of RNA solution was recovered after the elution step. Of the total RNA sample, $9 \mu 1$ were reversetranscribed in a final volume of $20 \mu \mathrm{l}$. The cDNA sample $(5 \mu \mathrm{l})$ was used for real-time PCR amplification. Values of Tankyrase-1 mRNA expression were corrected on the basis of the theoretical number of cells contained in the microdissected sample (n. cells $=$ microdissected area $\mu \mathrm{m}^{2} / 500 \mu \mathrm{m}^{2}$ ).

Statistical analyses. Statistical analysis was carried out using the SPSS software package (SPSS Inc., Chicago, IL). Statistical differences between groups were assessed by t-test analysis. For analysis of follow-up data, life table curves were calculated using the Kaplan-Meier method and survival distribution were comparated by log-rank statistics. The primary end point was cancer-related survival, as measured from the date of surgery to the time of last follow-up or cancer-related death. The joint effects with other variables were examined via Cox proportional hazard analysis. Differences were considered statistically significant at $\mathrm{p}<0.05$.

\section{Results}

Quantitative RT-PCR. Tankyrase-1 mRNA was expressed in $100 \%$ tumor samples and paired not affected tissues. The level of this expression was quite variable, ranging from 0.1 to $1210 \mathrm{ng}$ DU145 RNA/ $\mu \mathrm{g}$ total RNA for cancers and from 0.02 to 524 for paired unaffected samples, respectively. In $61 / 82(74 \%)$ of the paired samples, the expression in tumor was higher (at list twice) than in corresponding normal tissue and the mean levels of mRNA were significantly higher $(\mathrm{p}<0.0001)$ in cancer samples $(112.5 \pm 21.3 \mathrm{ng})$ than in corresponding normal counterparts $(49.6 \pm 9.6)$, with a mean cancer/normal tissue ratio of $8.9 \pm 2.0$.

Laser microdissection. In six random patients the laser dissected area was isolated in colon cancers. The peripheral zone of the tumor was chosed to prevent contamination by internal necrotic areas. In the same patients we isolated fragments of normal epithelium corresponding to the basal compartment of the crypts, the medium portion of crypt wall and the superficial luminal epithelium, according to the scheme reported in Fig. 1. Tankyrase-1 per cell mRNA espression was then calculated after correction with dissected area surface and mean cell diameter evaluation. Tankyrase- 1 mRNA expression decreases consistently from the basal compartment to the superficial epithelium, whereas the 
Table I. Tankyrase-1 mRNA expression in colorectal tumor and corresponding normal tissues, measured by quantitative RT-PCR

\begin{tabular}{|c|c|c|c|c|c|}
\hline & \multicolumn{5}{|c|}{ Tankyrase- 1 mRNA } \\
\hline & \multicolumn{3}{|c|}{ Expression in cancer tissue ${ }^{a}$} & \multicolumn{2}{|c|}{ Cancer/normal ratio } \\
\hline & $\mathrm{n}$ & Mean \pm SE & $\mathrm{p}$ & Mean \pm SE & $\mathrm{p}$ \\
\hline \multicolumn{6}{|l|}{ Age } \\
\hline$<55$ years & 6 & $87.8 \pm 34.6$ & & $2.1 \pm 1.1$ & \\
\hline$\geq 55$ years & 76 & $114.4 \pm 22.7$ & 0.746 & $9.3 \pm 2.2$ & 0.006 \\
\hline \multicolumn{6}{|l|}{ Gender } \\
\hline Male & 48 & $107.8 \pm 30.5$ & & $12.0 \pm 3.3$ & \\
\hline Female & 34 & $119.1 \pm 28.1$ & 0.795 & $4.2 \pm 1.1$ & 0.032 \\
\hline \multicolumn{6}{|l|}{ Localization } \\
\hline Right & 32 & $135.97 \pm 44.26$ & & $6.5 \pm 2.4$ & \\
\hline Left & 50 & $97.54 \pm 20.45$ & 0.381 & $10.3 \pm 3.0$ & 0.320 \\
\hline \multicolumn{6}{|c|}{ Pattern of growth } \\
\hline Infiltrating & 50 & $71.0 \pm 11.0$ & & $9.2 \pm 3.1$ & \\
\hline expanding & 32 & $189.5 \pm 54.2$ & 0.041 & $7.4 \pm 2.7$ & 0.678 \\
\hline \multicolumn{6}{|l|}{ Dukes } \\
\hline A-B & 52 & $126.4 \pm 31.6$ & & $8.9 \pm 2.0$ & \\
\hline C-D & 30 & $88.4 \pm 18.7$ & 0.391 & $8.8 \pm 4.5$ & 0.980 \\
\hline \multicolumn{6}{|l|}{ Grading } \\
\hline $\mathrm{G} 0 / \mathrm{G} 1$ & 17 & $170.7 \pm 50.5$ & & $10.3 \pm 3.6$ & \\
\hline G2/G3 & 65 & $93.1 \pm 24.8$ & 0.147 & $7.9 \pm 2.6$ & 0.633 \\
\hline \multicolumn{6}{|l|}{ Lymph nodes } \\
\hline Negative & 55 & $114.2 \pm 33.6$ & & $10.7 \pm 2.8$ & \\
\hline Positive & 27 & $112.2 \pm 30.9$ & 0.964 & $5.5 \pm 2.7$ & 0.190 \\
\hline \multicolumn{6}{|l|}{ Metastasis } \\
\hline Negative & 73 & $118.8 \pm 23.6$ & & $9.5 \pm 2.3$ & \\
\hline Positive & 9 & $61.5 \pm 18.6$ & 0.403 & $4.1 \pm 2.8$ & 0.155 \\
\hline \multicolumn{6}{|l|}{ CEA } \\
\hline$<5 \mathrm{ng} / \mathrm{ml}$ & 54 & $124.9 \pm 30.0$ & & $12.0 \pm 3.2$ & \\
\hline$\geq 5 \mathrm{ng} / \mathrm{ml}$ & 28 & $94.6 \pm 30.6$ & 0.526 & $4.0 \pm 1.4$ & 0.264 \\
\hline
\end{tabular}



espression in cancer samples is superimposable to that found in basal proliferating fondus of colon crypts (Fig. 1).

Tankyrase-1 mRNA and clinicopathological features. Table I shows the mean values of absolute expression of Tankyrase-1 mRNA in colon cancers and the ratio between cancers and normal tissues, stratified according to the clinicopathological features of our patients. Tankyrase-1 mRNA was significantly higher $(\mathrm{p}=0.041)$ in tumors with an expanding growth in comparison to cancer with an infiltrating pattern. A reduction of mRNA levels, although not statistically proven, appears constantly associated to more advanced cancers, as in Dukes C-D, in G2-G3, in metastatic cancers and in patients with high pre-operative CEA ( $>5 \mathrm{ng} / \mathrm{ml})$. This tendency to a reduction of Tankyrase-1 expression in more advanced colon cancer was confirmed by the ratio of Tankyrase- 1 expression between cancers and not affected tissues. The ratio was consistently reduced in low grade cancers, in $\mathrm{N}^{+}$or metastatic patients. The ratio was reduced to $1 / 3$ in patients with high CEA pre-operative concentrations, in subjects $<55$ years old and in females.

Survival analyses. The median follow-up duration of our patients was 43.8 months. Patients were stratified according to the median level of Tankyrase-1 mRNA expression (44 ng DU145 RNA/ $\mu \mathrm{g}$ total RNA). Survival analysis of cancerrelated death was obtained by comparing patients with high Tankyrase-1 mRNA ( $>$ median value) versus those with low expression ( $\leq$ median value). According to this division, we found that patients with lower levels of mRNA had a 
Table II. Univariate and multivariate Cox regression analysis for 82 patients with resected colon carcinoma.

\begin{tabular}{|c|c|c|c|c|}
\hline \multirow[b]{2}{*}{ Variable } & \multirow{2}{*}{$\frac{\text { Univariate analysis }}{\mathrm{p}}$} & \multicolumn{3}{|c|}{ Multivariate analysis } \\
\hline & & $\mathrm{p}$ & Relative Risk Exp(B) & $\operatorname{Exp}(\mathrm{B}) 95 \% \mathrm{Cl}$ \\
\hline \multicolumn{5}{|l|}{ Pattern of growth } \\
\hline Infiltrating vs. expanding & 0.048 & 0.114 & 0.179 & $0.021-1.511$ \\
\hline \multicolumn{5}{|l|}{ Dukes' stage } \\
\hline $\mathrm{A}+\mathrm{B}$ vs. $\mathrm{D}+\mathrm{C}$ & 0.022 & 0.283 & 2.123 & $0.537-8.395$ \\
\hline \multicolumn{5}{|l|}{ Tankyrase-1 mRNA ${ }^{a}$} \\
\hline High vs. low expression & 0.037 & 0.027 & 5.875 & $1.225-28.174$ \\
\hline
\end{tabular}

${ }^{a}$ Survival analysis of cancer-related death was obtained by comparing patients with high Tankyrase-1 mRNA ( $>$ median value: i.e., $>44$ ng DU145 RNA equivalents $/ \mu$ g total RNA) versus those with low expression ( $\leq$ median value).

significantly reduced overall survival (log-rank test, $\mathrm{p}=0.019)$ and a shorter disease-free survival ( $\mathrm{p}=0.035$ ) (Fig. 2).

A multivariate analysis was performed to evaluate whether the correlation between low Tankyrase expression and shortened cancer-related survival resulted from an association with other prognostically relevant factors. We found that low Tankyrase-1 mRNA expression, Dukes' stage (A-B versus C-D) and growth pattern (expanding vs. infiltrating), correlated significantly with overall survival in univariate Cox regression. Multivariate analysis demonstrated that high Tankyrase-1 expression was a significant and independent prognostic para-meter for shortened cancer-related survival in our patients $(\mathrm{p}=0.025)$. The relative risk for cancer-related death was 5.8 -fold increased in case of low Tankyrase-1 mRNA (Table II).

\section{Discussion}

It is evident that telomere maintenance has a pivotal role in the process of immortalization, chromosomal stability and tumorigenesis in humans (25). The upregulation or reactivation of a large number of factors maintaining telomere length appears as precocious events in cell transformation. The enzyme Tankyrase-1 was identified as a component of the human telomeric complex acting as a positive regulator of telomere length (13). This feature was confirmed in vivo (18). Tankyrase-1 is upregulated in multiple myeloma, plasma cell leukemia and high-grade non-Hodgkin's lymphomas (20-26); on the contrary, other authors failed to find Tankyrase-1 overexpression in gastric cancers $(27,28)$. In a very recent study, it was demonstrated that Tankyrase-1 up-regulation lessens the impact of telomerase inhibitors in vitro and that inhibition of Tankyrase-1 PARP activity restores telomerase shortening (29). These findings open new avenues in the assessment of combined antitumoral therapies to decrease telomere maintenance in cancer cells.

In a previous study we demonstrated that mRNA expression of Tankyrase-1 was up-regulated in breast cancer (21). Herein, we evaluated the expression of Tankyrase-1 mRNA in colon cancers and in corresponding apparent normal tissues. Tankyrase-1 mRNA was expressed in all samples and its expression was significantly higher in tumors in comparison to the corresponding normal adjacent samples. Interestingly, the level of expression of Tankyrase- 1 mRNA in colon cancer is, as a mean, about twice higher than in breast cancer. However, the mean increase of Tankyrase-1 mRNA in colon cancer, expressed as cancer/normal tissue ratio was very low $(8.9 \pm 2.0)$ in comparison to the equivalent ratio in breast cancers (327.6 \pm 205.5$)$ (21). This finding seems to indicate that, at least as a quantitative aspect, the up-regulation of Tankyrase-1 mRNA in colon cancer seems less evident and/or relevant.

To clarify the real entity of difference in Tankyrase-1 mRNA between normal and cancer tissue, we performed microdissection experiments to detect the expression of Tankyrase- 1 in isolated colon cancer cells as well as in normal epithelial cells collected in apparently normal colon crypts, $10 \mathrm{~cm}$ apart from the neoplasia. As expected, on the basis of the proposed role of Tankyrase-1 in maintaining telomere length, the maximal expression in normal crypts was found in the basal and proliferanting compartment of colonic crypt. The expression of Tankyrase-1 mRNA seems to decrease in the median and superficial compartment, paralleling the progression and differentiation of the same epithelial cells. Interestingly, the expression of Tankyrase-1 mRNA in microdissected cancer cells is higher than in normal not-proliferating epithelial cells, but not statistacally different from the expression of the basal compartment in normal colon crypts.

Absolute Tankyrase-1 mRNA expression had limited correlations with clinical and pathological features of our patients, even if a tendency to the reduction of mRNA appears constantly associated to more advanced cancers. Besides the absolute expression of Tankyrase-1, we also evaluated the ratio between cancer and paired not affected tissue. In our opinion, this method is the best approach to evaluate the levels of mRNA up-regulation for candidate genes in cancer samples, even if differences in cellular composition between colon cancer and paired normal tissue must be kept in mind. The ratio confirmed that more advanced colon cancers tend to reduce their Tankyrase-1 expression. This reduction was significant in younger patients $(<55)$ and in female patients.

Another finding supporting that the reduction of Tankyrase-1 expression is connected to cancer progression 
was the prognostic value of this parameter. Reduced levels of mRNA were associated to reduced patient survival and disease-free interval. Tankyrase-1 mRNA prognostic value was then confirmed in a multivariate analysis.

These data seem to indicate that the up-regulation of Tankyrase-1 in colon cancer cells is quantitatively less evident than in other human cancers (i.e. breast carcinoma) and not higher than in normally proliferating cells from the same tissue. The apparent association of reduced expression of Tankyrase- 1 in more advanced colon cancer seems to indicate that the up-regulation of this gene takes place only during the first phases of cancer progression, when the need of stabilizing telomeres might be maximal. In more advanced cancers, other mechanisms than Tankyrase-1 expression may be more relevant in cell immortalization and telomere maintainance.

\section{References}

1. Fearon ER and Vogelstein BA: Genetic model for colorectal tumorigenesis. Cell 61: 759-767, 1990.

2. Morson BC and Dawson IMP: Gastrointestinal Pathology, 2nd edition. Oxford, Blackwell Scientific Publications, pp615-647, 1979.

3. Rosen N: Molecular biology of gastrointestinal cancers. In: Cancer. de Vita VT Jr, Hellman S and Rosemberg SA (eds). Philadelphia-New York:Lippincott-Raven Publishers, NY, p971, 1997.

4. Shay JW, Zou Y, Hiyama E and Wright WE: Telomerase and cancer. Hum Mol Genet 10: 667-685, 2001.

5. Lustig AJ: Crisis intervention: The role of telomerase. Proc Natl Acad Sci USA 96: 3339-3341, 1999.

6. Smogorzewska A and de Lange T: Regulation of telomerase by telomeric proteins. Annu Rev Biochem 73: 177-208, 2004.

7. Gertler R, Rosemberg R, Stricker D, Friederichs J, Hoos A, Werner M, Ulm K, Holzmann B, Nekarda H and Siewert JR: Telomere lenght and human telomerase reverse transcriptase expression as markers for progression and prognosis of colorectal carcinoma. J Clin Oncol 22: 1807-1814, 2004.

8. Cong YS, Wright W and Shay JW: Human telomerase and its regulation. Microbiol Mol Biol Rev 66: 407-425, 2002.

9. Morales C, Holt E, Quellette M, Kaur KJ, Yan Y, Wilson KS, White MA, Wright WE and Shay JW: Absence of cancerassociated changes in human fibroblasts immortalized with telomerase. Nat Genet 21: 115-118, 1999.

10. Hahn WC, Dessain SK, Brooks MW, King JE, Elenbaas B, Sabatini DM, De Caprio JA and Weinberg RA: Enumeration of the simian virus 40 early region elements necessary for human cell trasformation. Mol Cell Biol 22: 2111-2123, 2002.

11. Haanh W, Counter CM, Lundber AS, Beijersbergen RL, Brooks MW and Weimberg RA: Creation of human tumor cells with defined genetic elements. Nature 400: 464-468, 1999.

12. Hiyama E, Hiyama K, Yokoyama T, Matsuura Y, Piatyszek MA and Shay JW: Correlating telomerase activity levels with human neuroblastoma outcomes. Nat Med 1: 249-255, 1995.

13. Smith S, Giriat I, Schmitt A and de Lange T: Tankyrase, a poly(ADP-ribose) polymerase at human telomeres. Science 282: 1484-1487, 1998.
14. Billaud T, Brun C, Anceli K, Koering CE, Laroche T and Gilson E: Telomeric localization of TRF2, a novel human telobox protein. Nat Genet 17: 236-239, 1997.

15. van Steensel B and de Lange T: Control of telomere length by the human telomeric protein. Nature 385: 740-743, 1997.

16. Smogorzewska A, van Steensel B, Bianchi A, Oelmann S, Schaefer M, Schnapp G and de Lange T: Control of human telomere length by TRF1 and TRF2. Mol Cell Biol 20: 1659$1668,2000$.

17. Karlseder J, Smogorzewska A and de Lange T: Senescence induced by altered telomere state, not telomere loss. Science 295: 2446-2449, 2002.

18. Smith $\mathrm{S}$ and de Lange T: Tankyrase promotes telomere elongation in human cells. Curr Biol 10: 1299-1302, 2000.

19. Xu D, Zheng C, Bergenbrant S, Holm G, Bjorkholm M, Yi Q and Gruber A: Telomerase activity in plasma cell dyscrasias. $\mathrm{Br}$ J Cancer 84: 621-625, 2001.

20. MacNamara B, Xu D, Wang W, Chen Z, Hou M, Mazur J, Gruber A and Porwit-MacDonald A: Telomerase activity in relation to pro- and anti-apoptotic protein expression in high grade non-Hodgkin's lymphomas. Haematologica 86: 386-393, 2001 .

21. Gelmini S, Poggesi M, Distante V, Bianchi S, Simi L, Luconi M, Casini Raggi C, Cataliott L, Pazzagli M and Orlando C: Tankyrase, a positive regulator of telomere elongation, is overexpressed in human breast cancer. Cancer Lett 216: 81-87, 2004.

22. WHO: Histological typing of intestinal tumors. In: International Histological Classifications of Tumors. Jass JR and Sobin LH (eds). 2nd edition. Springer-Verlag, Berlin, 1989.

23. Cianchi F, Messerini L, Palomba A, Boddi V, Perigli G, Pucciani F, Bechi $\mathrm{P}$ and Cortesini C: Character of the invasive margin in colorectal cancer. Does it improve prognostic information of Dukes' Staging? Dis Colon Rectum 40: 1170-1176, 1997.

24. Lyons RJ, Deane R, Lynch D, Ye ZS, Sanderson GM, Eyre HJ, Sutherland GR and Daly RJ: Identification of a novel human tankyrase through its interaction with the adapter protein Grb14. J Biol Chem 276: 17172-17180, 2001.

25. Artandi SE and DePinho RA: A critical role of telomeres in suppressing and facilitating carcinogenesis. Curr Opin Gen Dev 10: 39-46, 2000.

26. Klapper W, Krams M, Qian WD, Janssen D and Parwaresch R: Telomerase activity in B-cell non-Hodgkin lymphomas is regulated by hTERT transcription and correlated with telomerebinding protein expression but uncoupled from proliferation. $\mathrm{Br}$ J Cancer 89: 713-719, 2003.

27. Yamada M, Tsuji N, Nakamura M, Moriai R, Kobayashi D and Watanabe N: Down-regulation of TRF1, TRF2 and TIN2 genes is important to maintain telomeric DNA for gastric cancers. Anticancer Res 22: 3303-3307, 2002.

28. Matsutani M, Yokozaki H, Tahara E, Tahara H, Kuniyasu H, Kitadai Y, Haruma K, Chayama K, Tahara E and Yasui W: Expression of MRE11 complex (MRE11, RAD50, NBS1) and hRap1 and its relation with telomere regulation, telomerase activity in human gastric carcinomas. Pathobiology 69: 219-224, 2001.

29. Seimiya H, Muramatsu Y, Ohishi T and Tsuruo T: Tankyrase 1 as a target for telomere-directed molecular cancer therapeutics. Cancer Cell 7: 25-37, 2005. 